\title{
Does where you live matter? Leisure-time physical activity among Canadian youth: a multiple cross-sectional study
}

\author{
Charles Nadeau MSc, Laurence Letarte MSc, Ramona Fratu MSc, E. Owen D. Waygood PhD, \\ Alexandre Lebel PhD
}

\section{Abstract}

Background: The aim of this study was to explore the population-wide distribution in the practice of leisure-time physical activity among Canadian youth and how physical activity level is influenced by contextual features of the environment.

Methods: We studied the self-reported leisure-time physical activity of 54832 Canadians aged 12 to 17 years. Observations were structured according to a 4-level geographic hierarchy. The outcome studied was a dichotomous indicator that referred to achieving (or not) the recommended daily level of leisure-time physical activity. To investigate the influence of the contextual features, we conducted multilevel logistic regressions.

Results: For both girls and boys, significant variations were observed between health regions and between neighbourhoods within the provinces. Girls who lived in an urban setting showed lower odds of achieving the recommended physical activity level, as did those surveyed during the winter. Boys surveyed during the winter also showed lower odds of achieving the recommended level, but living in an urban setting had no effect on activity levels. Analysis of province-level residuals showed that girls living in Quebec were less likely to achieve the recommended activity level as compared with the national mean, and girls living in Ontario and British Columbia were more likely to achieve that threshold. Boys living in Ontario were more likely to achieve the recommended activity level as compared with the national mean. Youth had up to a $17 \%$ increased chance of achieving the recommended physical activity level if they lived in a context with a higher activity achievement level.

Interpretation: Leisure-time physical activity was associated with environmental factors at multiple geographic scales among Canadian youth. The variation was more important at the neighbourhood level. The results provide rationale for further investigation into how leisure-time physical activity is promoted in different contexts.

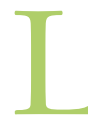
eisure-time physical activity (LPA) provides fundamental health benefits for young people, ${ }^{1}$ including increased physical fitness, reduced adiposity, favourable risk profiles for cardiovascular and metabolic disease, and reduced symptoms of depression. ${ }^{2-5}$ Among young people, the growth period is a critical time for the development of factors that have a great influence on health in adulthood, such as achieving optimal bone health. ${ }^{6}$

Understanding what influences youth to engage in LPA contributes to evidence-based planning of public health interventions, as effective programs will target factors known to contribute to physical (in)activity. ${ }^{7}$ Research into correlates or determinants of LPA has focused mostly on individual-level factors. ${ }^{8}$ Among them, indicators of socioeconomic status such as education ${ }^{9}$ and biological factors such as body mass index ${ }^{10}$ have been associated with differences in participation in LPA. However, contextual factors such as the quality of the built or social environment are less studied but are thought to have widespread effects that may vary across geographic settings. ${ }^{8,11,12}$
A better understanding of the influence of geographic settings (local to national) on LPA among youth can inform the development of multifaceted interventions, which likely offer the best chance for success. ${ }^{13}$

The aim of this study was to explore the population-wide distribution of LPA among young Canadians and the influence of area-based characteristics, while taking into account individual factors. The objectives were to describe the geographic variations in LPA among Canadian youth and explore the contribution of contextual factors to explain these variations.

\section{Competing interests: None declared.}

This article has been peer reviewed.

Correspondence to: Alexandre Lebel, alexandre.lebel@criucpq.ulaval. ca

CMAJ Open 2016. DOI:10.9778/cmajo.20150089 


\section{Methods}

\section{Data source, study population and sample size}

We used the Canadian Community Health Survey (CCHS), 2003 to 2012. The CCHS provides self-reported information for a nationally representative sample of the communitydwelling civilian population aged 12 years or more in the 10 Canadian provinces. ${ }^{14}$ The sample for this study included youth aged 12-17 years for whom complete information on ethnic origin, education level, body mass index and geographic location was available. Pregnant girls and respondents interviewed by proxy were excluded.

\section{Structure of observations}

We structured observations according to a 4-level geographic hierarchy based on Statistics Canada 2006 census administrative units. When a place of residence was located in a census metropolitan area or a census agglomeration, the "neighbourhood" corresponded to the census tract; otherwise it was attributed to the municipality (census subdivision). The combination of census tract and census subdivisions enables the creation of comparable neighbourhood units for the entire Canadian population, whether they are located in an urban or a rural setting, and to consider the idiosyncrasies of the characteristics of place of residence. To take into account changes in the boundaries of the health regions during the study period, we harmonized the geographic structure using a digital boundary file reflecting the boundaries of the health regions as of October 2011. ${ }^{15} \mathrm{~A}$ detailed methodology of the geographic structure has been given by Lalonde and Lebel. ${ }^{16}$ We used ArcMap 10.1 software for geospatial processing. The final hierarchical structure comprised 6004 neighbourhoods within 112 health regions.

\section{Outcome}

The dependant variable was a dichotomous indicator of LPA that refers to achieving (or not) the recommended daily level of physical activity. Physical activity level was assessed with the use of an index based on 18 different physical activities for which duration, intensity and energy expenditure were considered. ${ }^{17}$ Guidelines recommend that young people aged 12-17 should accumulate an average of at least 60 minutes of moderate to vigorous physical activity daily. ${ }^{18,19}$ An "active" youth is one who achieves an index of energy expenditure of at least $30 \mathrm{kcal} /$ $\mathrm{kg}$ per week $\mathrm{k}^{17}$ with a frequency of 5 times/week or more. This achievement corresponds to walking briskly ( 4.3 metabolic equivalents) for 1 hour a day, 7 days a week..$^{20}$ We estimated physical activity level using a validated index of energy expenditure that considers the frequency, duration and intensity of 18 types of self-reported LPA. ${ }^{21}$ Given the absence of a measure of exercise intensity in the CCHS, we derived thresholds from a table of metabolic equivalents for various activities. ${ }^{21}$

\section{Individual variables}

To account for the documented influences of individual characteristics on LPA among youth, ${ }^{22-24}$ we used age, ethnic origin, highest education level of the household and body mass index (based on self-reported height and weight) as control variables.

\section{Cycle and season}

The CCHS contains data collected over 12 months (cycle 2003 and 2005) and 24 months (cycle 2007, 2009 and 2011). The exact date of sampling allowed for the inclusion of season in the explanatory model. Three season categories were created: summer (July to October), winter (February and March) and transitional (combining November to January and April to June).

\section{Area-based variables}

We considered 3 independent area-based variables. The first was the census metropolitan-influenced zone, which indicates areas that are urban (inside census metropolitan areas or census agglomerations), urban outskirt (commuting flow to urban area $30 \%$ or more) and rural (commuting flow to urban area less than $30 \%) .25$

The 2 other area-based variables were the neighbourhood material and social deprivation levels. The measures of deprivation are based on the factor score of 2 dimensions resulting from a principal component analysis that estimates the material and social deprivation of the neighbourhood using Canada-wide census information (proportions of adults who live alone, are single parents, do not have a high school diploma and are unemployed, and the mean income of the area). ${ }^{26}$ The distribution of the neighbourhood deprivation levels was broken into quintiles by province for all census units.

\section{Statistical analysis}

We used multilevel analysis to estimate the impact of contextual factors on LPA. The use of multilevel analysis is recommended to account for the clustering of people within areas and to break down the variance in the outcome being studied into between- and within-area components..$^{27,28}$ Thus, to investigate the influence of the contextual variables, we conducted a series of multilevel logistic regression analyses using the Bayesian estimation procedure as implemented via Markov chain Monte Carlo methods in MLwiN 2.28 software. ${ }^{29}$ The benefits of this type of analysis as compared to a standard logistic regression are to produce unbiased estimates of the random effects and to provide a measure to compare the relative effectiveness of different models in accounting for the variations in LPA, the deviance information criterion. ${ }^{27}$

All analyses were stratified by sex to control for the differences in physical maturation between girls and boys during puberty. ${ }^{30}$

The modelling strategy was based on 4 incremental models to estimate the effect of the additional groups of variables in the fixed part of the models on the between-area variance (random part of the models). The equation for the models is provided in Appendix 1 (available at www.cmajopen.ca/content/4/3/E436/ suppl/DC1). The first (null) model showed the distribution of LPA between the geographic levels (random part) without covariates. The second model introduced the control variables of cycle and season, the third model introduced the metropolitan-influenced zone, and the fourth model introduced the neighbourhood material and social deprivation indices.

We used the deviance information criterion to compare the goodness of fit $^{31}$ of each model with that of the previous model 


\section{OPEN}

Research

( $\Delta$ deviance information criterion). We used the median odds ratio $(\mathrm{OR})$ to translate the area-level variance to an $\mathrm{OR}$ scale, which has a consistent and intuitive interpretation. ${ }^{32}$ The median OR can be compared directly with a regular OR and allows one to estimate the relative importance of the unexplained area-level variation (here province, health region and neighbourhood) compared with other variables included in the model. Variation in the median OR was considered significant when 1.96 times its standard error (SE) remained lower than the between-area variance.

All the models present the odds of achieving the recommended LPA for each characteristic considered (fixed part). We analyzed the between-area variance structure (random part) using the median OR (i.e., province, health region and neighbourhood).

Apart from the null model, the reference category was age 12-15 years, white, living in a highly educated household, reporting a normal weight, surveyed during summer, living in an urban setting (for models 3 and 4) and living in the leastdeprived neighbourhoods (model 4).

We used the province-level residuals and associated SE to plot and rank the odds (and 95\% confidence interval [CI]) of achieving the LPA threshold for each province. In this way, provinces that differed from the national mean (individual, neighbourhood and regional effects) could easily be identified.

\section{Resullts}

The final sample was 54832 observations. The distribution of all variables used in the analyses is found in Table 1. Apart from body mass index, where some substantial differences were observed, the distributions were comparable for the 2 sexes. The largest difference was in the outcome: 9908 girls $(36.9 \%)$ and 14540 boys (51.9\%) achieved the recommended LPA level (Table 1).

\section{Models on girls' leisure-time physical activity}

For girls, the null model showed a significant difference in achieving the recommended LPA level between health regions and neighbourhoods but not between provinces (Table 2, random part). Introducing individual characteristics (model 2), and thus controlling for age, ethnic origin and body mass index, showed lower odds of achieving the recommended LPA level among girls surveyed during winter (OR 0.58, 95\% CI 0.54 0.62 ) or the transitional season (OR $0.66,95 \%$ CI $0.62-0.70)$ as compared to summer. No differences in LPA level were observed over the study period, but significant variation between health regions remained.

Introducing the metropolitan-influenced zone of the neighbourhood (i.e., urban, urban outskirt or rural) (model 3) suggested that a lower likelihood of achieving the recommended LPA level existed for girls in urban areas compared with those in urban outskirt areas (OR 1.12, 95\% CI 1.04-1.21) or rural areas (OR 1.13, 95\% CI 1.04-1.23). Furthermore, the location of the neighbourhood did not explain much of the significant variation observed between health regions ( $\operatorname{Var} 0.014$, SE 0.005), but there was an important increase in the variation explained at the
Table 1: Distribution of outcome (achieved recommended daily level of leisure-time physical activity) and covariates for girls and boys

\begin{tabular}{|c|c|c|}
\hline \multirow[b]{2}{*}{ Variable } & \multicolumn{2}{|c|}{$\%$ of children } \\
\hline & $\begin{array}{c}\text { Girls } \\
n=26822\end{array}$ & $\begin{array}{c}\text { Boys } \\
n=28010\end{array}$ \\
\hline Outcome & 36.9 & 51.9 \\
\hline \multicolumn{3}{|l|}{ Individual variables } \\
\hline \multicolumn{3}{|l|}{ Age, yr } \\
\hline $12-15$ & 65.8 & 66.0 \\
\hline $16-17$ & 34.2 & 34.0 \\
\hline \multicolumn{3}{|l|}{ Ethnicity } \\
\hline White & 74.6 & 73.9 \\
\hline Asian & 10.4 & 11.0 \\
\hline Other & 8.6 & 8.6 \\
\hline Unknown & 6.4 & 6.5 \\
\hline \multicolumn{3}{|l|}{ Household education level } \\
\hline University & 33.0 & 33.2 \\
\hline High school/college & 49.8 & 49.0 \\
\hline Less than high school & 3.6 & 3.6 \\
\hline Unknown & 13.7 & 14.2 \\
\hline \multicolumn{3}{|l|}{ Body mass index } \\
\hline Normal weight & 68.0 & 65.7 \\
\hline Underweight & 10.8 & 5.8 \\
\hline Overweight & 10.7 & 17.3 \\
\hline Obese & 2.8 & 5.4 \\
\hline Unknown & 7.6 & 5.8 \\
\hline \multicolumn{3}{|l|}{ Cycle and season } \\
\hline \multicolumn{3}{|l|}{ Cycle } \\
\hline 2003-2004 & 23.4 & 23.7 \\
\hline 2005-2006 & 21.3 & 21.0 \\
\hline $2007-2008$ & 18.9 & 18.6 \\
\hline 2009-2010 & 18.7 & 18.8 \\
\hline 2011-2012 & 17.8 & 17.9 \\
\hline \multicolumn{3}{|l|}{ Season } \\
\hline Summer & 34.4 & 34.2 \\
\hline Winter & 18.2 & 18.4 \\
\hline Transitional & 47.3 & 47.4 \\
\hline \multicolumn{3}{|l|}{ Area-based variables } \\
\hline \multicolumn{3}{|c|}{ Metropolitan-influenced zone } \\
\hline Urban & 80.6 & 81.2 \\
\hline Urban outskirt & 12.1 & 11.8 \\
\hline Rural & 7.2 & 7.1 \\
\hline \multicolumn{3}{|l|}{ Material deprivation quintile } \\
\hline Most privileged & 17.4 & 16.5 \\
\hline Privileged & 22.5 & 23.3 \\
\hline Median & 28.2 & 28.5 \\
\hline Deprived & 21.2 & 21.1 \\
\hline Most deprived & 10.8 & 10.5 \\
\hline \multicolumn{3}{|l|}{ Social deprivation quintile } \\
\hline Most privileged & 12.9 & 12.6 \\
\hline Privileged & 23.6 & 24.0 \\
\hline Median & 27.7 & 27.2 \\
\hline Deprived & 24.8 & 23.9 \\
\hline Most deprived & 11.1 & 12.2 \\
\hline
\end{tabular}




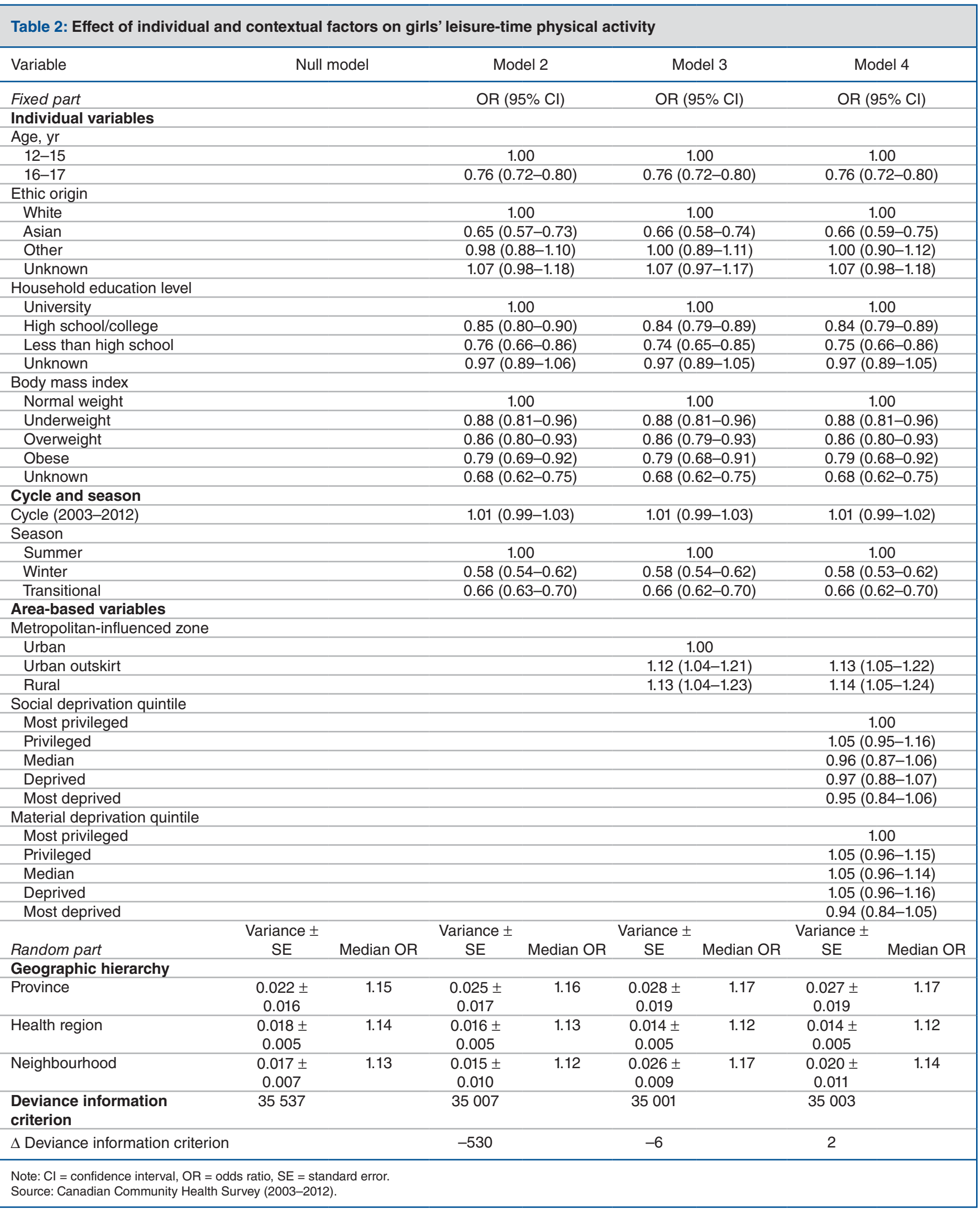


neighbourhood level (Var 0.026, SE 0.009). The median OR indicated that girls living in an urban neighbourhood had a $12 \%$ increased chance of achieving the recommended LPA level if they lived in a health region with a higher achievement of recommended LPA level (median OR 1.12) and a 17\% increased chance if they lived in a province with a higher achievement level (median OR 1.17).

Introducing the deprivation level of the neighbourhood (model 4) showed no significant association in achieving the recommended LPA level and reduced goodness of fit as compared with model 3 (Table 2).

\section{Models on boys' leisure-time physical activity}

For boys, the null model showed a significant difference in achieving the recommended LPA level only between health regions (Table 3). Introducing individual characteristics and season (model 2) showed lower odds of achieving the recommended LPA level among boys surveyed during winter (OR 0.55, 95\% CI $0.51-0.59$ ) or the transitional season (OR 0.70, 95\% CI 0.670.74 ) as compared with summer. A slight but statistically significant decrease in LPA was observed from 2003 to 2012 (OR 0.98, 95\% CI 0.96-0.99). Importantly, the individual characteristics improved the goodness of fit of the model but did not explain the variation between health regions, which suggests a homogeneous distribution of these characteristics between areas.

Unlike for girls, type of neighbourhood was not associated with the odds of achieving the recommended LPA level (model 3). Nevertheless, the model showed significant variation between health regions (Var 0.017, SE 0.005) and between neighbourhoods (Var 0.023, SE 0.009) within provinces. The median OR indicated that boys had a $13 \%$ increased chance of achieving the recommended LPA level if they lived in a health region with a higher achievement of recommended LPA level (median OR 1.13 ) and a $16 \%$ increased chance if they lived in a neighbourhood with a higher achievement level (median OR 1.16).

The deprivation level of the neighbourhood (model 4) showed no significant association with achieving the recommended level of LPA and reduced the goodness of fit as compared with model 3 (Table 3).

\section{Variation between provinces}

Analysis of province-level residuals showed that girls living in Quebec were less likely to achieve the recommended level as compared with the national mean, and girls living in Ontario and British Columbia were more likely to achieve that threshold (Figure 1). Boys living in Ontario were more likely to achieve the recommended LPA level as compared with the national mean (Figure 1).

\section{Interpretation}

In this study, we explored differences in reported LPA among Canadian youth according to their geographic context and focused mainly on contextual factors. We applied a 4-level model that controlled for age, ethnic origin, household education level and body mass index. We found that, beyond individual characteristics, the contextual characteristics were associated with the odds of accumulating an energy equivalent of at least 60 minutes of moderate to vigorous LPA. Moreover, these contextual influences were sometimes different between girls and boys.

As in other Canadian investigations, ${ }^{33,34}$ substantially fewer girls than boys achieved the recommended LPA level $(36.9 \%$ v. $51.9 \%)$. This finding reinforces the need to consider sex-specific requirements when planning public health interventions related to LPA. A proposed area of improvement involves strategies to ensure equitable access to resources, including availability of and access to suitable physical education classes and organized sports that may be subject to sex-related inequities. ${ }^{35,36}$

Season had a highly significant influence. For both sexes, winter was observed as a major barrier to performing LPA, even when the potential addition of compulsory physical education classes was taken into account. This finding supports previous evidence of an influence of seasonality on LPA among various populations, including young Canadians. ${ }^{37,38}$ For this reason, seasonality needs to be taken into account when developing interventions and programs targeting physical activity.

Contrary to previous findings, ${ }^{39}$ living in an urban outskirt or rural area as compared to an urban neighbourhood was associated with higher odds of meeting physical activity guidelines among girls. This observation suggests that facilities in urban areas may be more suitable for boys, ${ }^{40}$ for whom this measure was not significant in our study. Analysis of the between-neighbourhood variance showed that most of the variation in LPA among Canadian youth occurred between urban neighbourhoods. This suggests that greater inequalities in opportunities for LPA exist in urban neighbourhoods.

The relatively poor odds of achieving the recommended LPA level among girls living in Quebec seen on analysis of provincial-level residuals raises the question as to why girls in that province tend to be less active than other Canadian girls. Investigation is warranted into how physical activity is promoted in Quebec as compared to in Ontario and British Columbia, where girls had higher LPA levels than the national mean.

The introduction of area-based indices of material and social deprivation led to poorer goodness of fit of the overall models. As such, we have drawn no conclusions about their association with the odds of achieving the LPA guidelines. A recent analysis of the influence of these indices among Quebec high school students showed that those from materially and socially privileged backgrounds were proportionally more active than those from disadvantaged backgrounds. ${ }^{41} \mathrm{How}$ ever, the authors did not account for the country-wide variation and the hierarchical structure of the information. More context-specific investigations are required to explore the causes of these contrasting observations.

\section{Limitations}

Several limitations need to be kept in mind when interpreting our results. Although the sample was distributed over a 10 -year period, the cross-sectional design of the study limits our ability to establish causal inferences, particularly with respect to contextual effects. Also, the CCHS data on LPA aim to account for all activities completed over a 3-month 


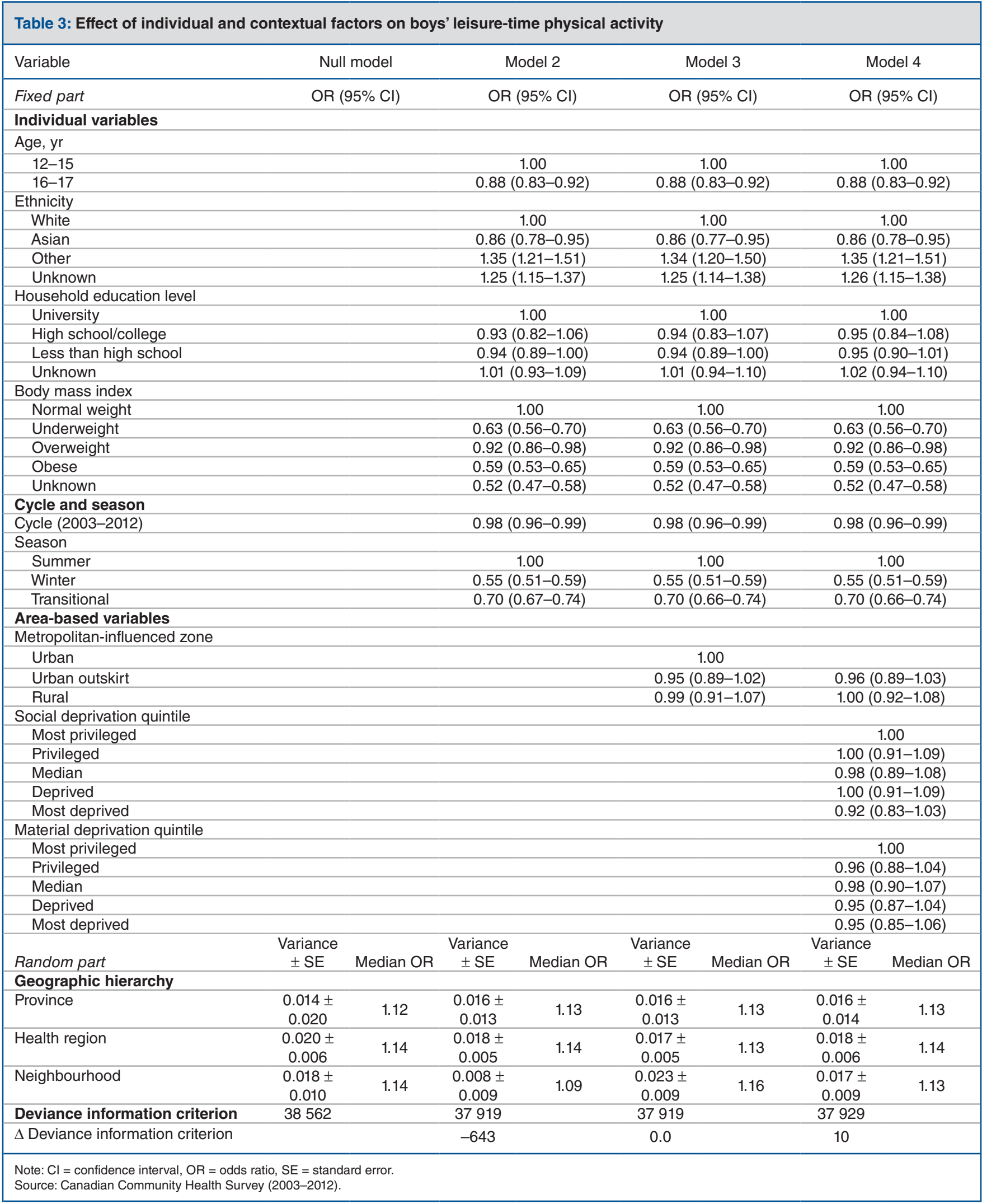



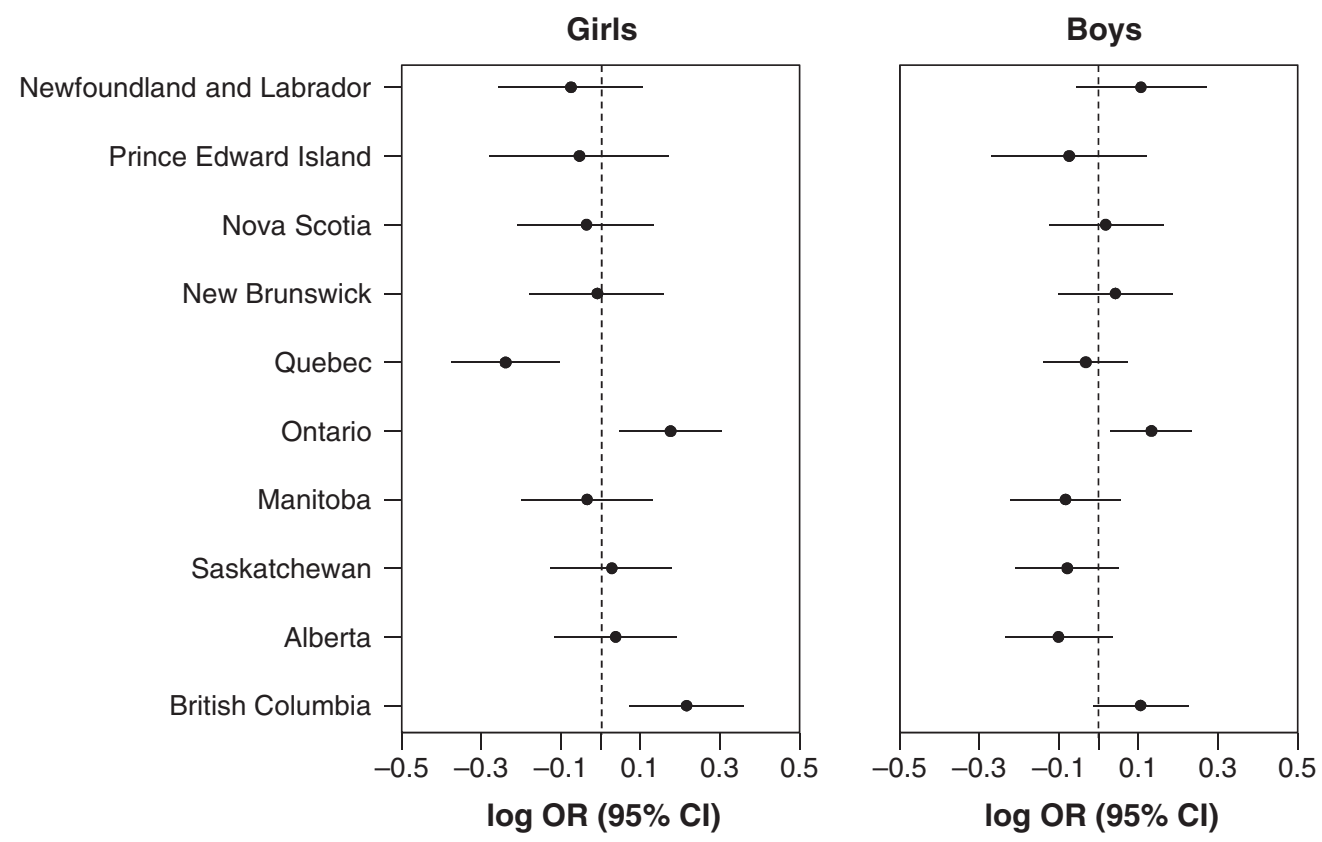

Figure 1: Province-level residuals of the logarithm of the odds ratio (OR) for achieving the recommended level of leisure-time physical activity among girls and boys. $\mathrm{Cl}=$ confidence interval.

period before the administration of the survey. For that reason, the accuracy of recall regarding duration and frequency of physical activity is questionable, as recall of nonrepeating activities would likely be more difficult and there would likely be a bias toward LPA in which participants are registered (e.g., lessons, league sports). Also, the survey does not indicate whether the activity is performed as part of a compulsory physical education class, even though that might have a significant influence on the age group studied. Last, we did not account for physical activity performed for utilitarian purposes such as active transport, which is more common in central, often deprived, neighbourhoods. ${ }^{42}$ The inclusion of this type of activity would have given a more complete picture of daily physical activity and may have enhanced the effects of contextual features.

\section{Conclusion}

This exploratory analysis provides insight into the contextual differences regarding the level of LPA among Canadian youth based on a large sample, a combination of individual and contextual information, and a multilevel framework. The results highlight important inequalities in LPA levels among Canadian youth and show context-specific variations between provinces, health regions and neighbourhoods. These findings provide valuable new information to guide future research aimed at better understanding why young people's LPA levels are unequally distributed in Canada.

\section{References}

1. Global recommendations on physical activity for bealth. Geneva: World Health Organization; 2010.

2. Janssen I. Physical activity guidelines for children and youth. Can 7 Public Health 2007;98(Suppl 2):S109-21.

3. Janssen I, Leblanc AG. Systematic review of the health benefits of physical activity and fitness in school-aged children and youth. Int 7 Behav Nutr Phys Act 2010;7:40.

4. Physical Activity Guidelines Advisory Committee report. Washington: US Department of Health and Human Services; 2008.

5. Warburton DE, Nicol CW, Bredin SS. Health benefits of physical activity: the evidence. CMA7 2006;174:801-9.

6. L'activité physique et la santé osseuse: avis du Comité scientifique de KinoQuébec. Québec: Ministère de l'Éducation, du Loisir et du Sport; 2008.

7. Sallis JF, Owne N, Fotheringham MJ. Behavioral epidemiology: a systematic framework to classify phases of research on health promotion and disease prevention. Ann Behav Med 2000;22:294-8.

8. Bauman AE, Reis RS, Sallis JF, et al. Correlates of physical activity: Why are some people physically active and others not? Lancet 2012;380:258-71.

9. Van Der Horst K, Paw M, Twisk JW, et al. A brief review on correlates of physical activity and sedentariness in youth. Med Sci Sports Exerc 2007;39:1241-50.

10. Patnode CD, Lytle LA, Erickson DJ, et al. The relative influence of demographic, individual, social, and environmental factors on physical activity among boys and girls. Int 7 Behav Nutr Phys Act 2010;7:79.

11. Dahlgren G, Whitehead M. Policies and strategies to promote social equity in health. Stockholm: Institute for Future Studies; 1991

12. Merlo J. Contextual influences on the individual life course: building a research framework for social epidemiology. Psychosoc Intervent 2011;20:109-18.

13. Sallis JF, Owen N, Fisher EB. Ecological models of health behavior. In: Glanz K, Rimer BK, Viswanath K, editors. Health behavior and health education: theory, research, and practice. 4th ed. San Francisco: Wiley; 2008:465-86.

14. Canadian Community Health Survey - annual component. Ottawa: Statistics Canada; 2014.

15. Health regions: boundaries and correspondence with census geography. Ottawa: Statistics Canada; 2011.

16. Lalonde B, Lebel A. Indicateurs socioéconomiques pour les communautés canadiennes. Rapport méthodologique. Québec: Plateforme d'évaluation en prévention de l'obésité; 2015. 
17. Nolin B. Index of physical activity: codification, criteria and algorithm Quebec Health Survey of high school students 2010-2011. Québec: National Public Health Institute of Quebec; 2012.

18. Canadian physical activity guidelines: clinical practice guidelines report. Ottawa: Canadian Society for Exercise Physiology; 2011.

19. Tremblay MS, Warburton DER, Janssen I, et al. New Canadian physical activity guidelines. Appl Physiol Nutr Metab 2011;36:36-46.

20. Ainsworth BE, Haskell WL, Herrmann SD, et al. 2011 Compendium of Physical Activities: a second update of codes and MET values. Med Sci Sports Exerc 2011;43:1575-81.

21. Nolin B. Recreational physical activity: codification and analysis criteria Quebec surveillance system determinants of health. Québec: National Public Health Institute of Quebec; 2004.

22. Gortmaker SL, Lee R, Cradock AL, et al. Disparities in youth physical activity in the United States: 2003-2006. Med Sci Sports Exerc 2012;44:888-93.

23. Nader PR, Bradley RH, Houts RM, et al. Moderate-to-vigorous physical activity from ages 9 to 15 years. FAMA 2008;300:295-305.

24. Whitt-Glover MC, Taylor WC, Floyd MF, et al. Disparities in physical activity and sedentary behaviors among US children and adolescents: prevalence, correlates, and intervention implications. F Public Health Policy 2009;30(Suppl 1):S309-34.

25. McNiven C, Puderer H, Janes D. Census metropolitan area and census agglomeration influenced zones (MIZ): a description of the methodology. Geography working paper series. Ottawa: Statistics Canada; 2000. Cat no 92F0138MIE.

26. Pampalon R, Raymond G. Indice de défavorisation matérielle et sociale: son application au secteur de la santé et du bien-être. Santé Soc Solidarité 2003;1:191-208.

27. Subramanian SV, Jones K, Kaddour A, et al. Revisiting Robinson: the perils of individualistic and ecologic fallacy. Int 7 Epidemiol 2009;38:342-60.

28. Diez Roux AV. A glossary for multilevel analysis. 7 Epidemiol Community Health 2002;56:588-94.

29. Browne WJ. MCMC estimation in MLwiN, v2.26. Bristol (UK): University of Bristol; 2014.

30. Duncan JS, Schofield G, Duncan EK. Step count recommendations for children based on body fat. Prev Med 2007;44:42-4.

31. Spiegelhalter DJ, Best NG, Carlin BP, et al. Bayesian measures of model complexity and fit. $\mathcal{F}$ R Statist Soc B 2002;64:583-639.

32. Merlo J, Chaix B, Ohlsson H, et al. A brief conceptual tutorial of multilevel analysis in social epidemiology: using measures of clustering in multilevel logistic regression to investigate contextual phenomena. 7 Epidemiol Community Health 2006;60:290-7.

33. Godin G, Anderson D, Lambert LD, et al. Identifying factors associated with regular physical activity in leisure time among Canadian adolescents. Am 7 Health Promot 2005;20:20-7.

34. Colley RC, Garriguet D, Janssen I, et al. Physical activity of Canadian children and youth: accelerometer results from the 2007 to 2009 Canadian Health Measures Survey. Ottawa: Statistics Canada; 2011. Cat no 82-625-X.
35. Butler GP, Orpana HM, Wiens AJ. By your own two feet: factors associated with active transportation in Canada. Can 7 Public Health 2007;98:259-64.

36. Veugelers PJ, Fitzgerald AL. Prevalence of and risk factors for childhood overweight and obesity. CMA7 2005;173:607-13.

37. Tucker P, Gilliland J. The effect of season and weather on physical activity: a systematic review. Public Health 2007;121:909-22.

38. Bélanger M, Gray-Donald K, O'Loughlin J, et al. Influence of weather conditions and season on physical activity in adolescents. Ann Epidemiol 2009;19:180-6.

39. Bruner MW, Lawson J, Pickett W, et al. Rural Canadian adolescents are more likely to be obese compared with urban adolescents. Int 7 Pediatr Obes 2008;3: 205-11.

40. Dunton GF, Jamner MS, Cooper DM. Assessing the perceived environment among minimally active adolescent girls: validity and relations to physical activity outcomes. Am 7 Health Promot 2003;18:70-3

41. Traoré I, Nolin B, Pica LA. Activité physique de loisirs et de transport. In: L'Enquête québécoise sur la santé des jeunes du secondaire 2010-2011. Québec: Institut de la statistique du Québec; 2012.

42. Pabayo RA, Gauvin L, Barnett TA, et al. Understanding the determinants of active transportation to school among children: evidence of environmental injustice from the Quebec Longitudinal Study of Child Development. Health Place 2012;18:163-71.

Affiliations: Quebec Heart and Lung Institute, Evaluation Platform on Obesity Prevention (Nadeau, Letarte, Fratu, Lebel); École supérieur d'aménagement du territoire et de développement régional (Nadeau, Letarte, Fratu, Waygood, Lebel), Laval University, Québec, Que.

Contributors: Charles Nadeau, Owen Waygood and Alexandre Lebel conceived and designed the study. Charles Nadeau, Ramona Fratu and Alexandre Lebel obtained access to the data, and Charles Nadeau and Ramona Fratu performed the statistical analyses. All of the authors contributed to the interpretation of the results, drafting the paper and reviewing it critically for inportant intellectual content. All of the authors gave approval of the final version to be published and agreed to act as guarantors of the work.

Funding: This study was partly funded by the Evaluation Platform on Obesity Prevention in the Quebec Heart and Lung Institute Research Center, Laval University, and the Fonds de recherche du Québec - Santé (grant number FRQS-31022).

Supplemental information: For reviewer comments and the original submission of this manuscript, please see www.cmajopen.ca/content/4/3/ E436/suppl/DC1 